placebo-controlled study assessing the safety and tolerability of the switch in treatment from the tricyclic antidepressants amitriptyline and clomipramine to moclobemide, no clinically relevant interaction was noted. Therapeutic doses of moclobemide up to $300 \mathrm{mg}$ could be given $24 \mathrm{hrs}$ after the last dose of amitriptyline or clomipramine without major risks. ${ }^{2}$ We report a case of serious hypertension after a previous treatment with clomipramine was washed-out before treatment with moclobemide was started.

A 23 year old woman, with baseline blood pressure of $110 / 75 \mathrm{~mm} \mathrm{Hg}$, was suffering from resistant major depression. She had received treatment with clomipramine for more than six months with doses up to $250 \mathrm{mg}$ /day, when it was decided to start a trial with moclobemide. Her concomitant treatment was beclomethasone inhaler and oral contraceptives. Clomipramine was gradually withdrawn over six days, and eight days after the last dose of clomipramine, moclobemide was started initially at $150 \mathrm{mg} /$ day then increased up to $300 \mathrm{mg} /$ day. A rise in blood pressure up to $170 / 120 \mathrm{~mm} \mathrm{Hg}$ was noted on day 16 of treatment with moclobemide. The patient started also complaining about severe headaches, blurred vision and restlessness. Initially, it was thought that the combination of the oral contraceptives were responsible for the patients headaches and hypertension and therefore, the treatment with oral contraceptives was stopped. Her blood pressure remained high intermittently up to $170 / 110 \mathrm{~mm} \mathrm{Hg}$ until it was decided to stop the treatment with moclobemide on day 21. By day 28, her blood pressure was still noted to be up to $150 / 100 \mathrm{~mm} \mathrm{Hg}$, however this gradually decreased to $120 / 80 \mathrm{~mm} \mathrm{Hg}$ on day 36 . Also, the treatment with the same oral contraceptives was restarted on day 51 without developing a similar hypertensive reaction. Finally, a treatment with sertraline was successfully introduced on which the patient's mental state improved considerably.

Despite the fact, that the United Kingdom recommended drug-free period of a week was kept after clomipramine was withdrawn, this may have been insufficient in our patient. Dingemanse et $a l^{2}$ only used clomipramine for 14 days at a dose of $100 \mathrm{mg} / \mathrm{day}$, before it was abruptly changed to moclobemide. Our patient, received clomipramine at doses of $200-250 \mathrm{mg} /$ day for more than six months before it was withdrawn. For the irreversible MAOIs the combination with clomipramine seems to require extra caution.' Recently the combination of moclobemide and clomipramine has also been associated with a severe hypertensive reaction. ${ }^{3}$ Therefore, blood pressure should be monitored when treating patients with moclobemide, especially when combining with or switching from clomipramine.

Therese van Amelsvoort, MRCPsych, Maudsley Hospital, Denmark Hill, London SE5 8 AZ, England.

References

1. Dingemanse J. An update of recent moclobemide interaction data. J Clin Psychopharmacol 1993; 7: 167-80.

2. Dingemanse J, Kneer J, Fotteler B, Groen H, Peeters PA, Jonkman JH. Switch in treatment from tricyclic antidepressants to moclobemide: a new generation monoamine oxidase inhibitor. I Clin Psychopharmacol 1995; 15(1): 41-8

3. Coulter DM, P! Pillans. Hypertension with modobemide. Lancet 1995; 346 ; 1032 .

\section{Suicide, depression and immunological resignation}

Sir-Abed's paper ${ }^{1}$ on suicide as altruism reconciles selfdestructive behaviour with the 'selfishness' of the gene,' thus clearing the way for an evolutionary hypothesis of depression which takes into account the associated increase in mortality. Suicide is but one of the fatal outcomes of depression and it may be through immunological changes that the depressed individual is disposed to illness and death. ${ }^{3}$ Depression facilitating death in the face of adversity with which the individual could not cope appeared to be an empirically testable challenge to the selfish gene hypothesis. ${ }^{3}$ However, Abed's neat extrapolation of "inclusive fitness" to explain suicide as potentially enhancing the likelihood of survival of the individual's genes, present in his kin, would offer an alternative and more satisfying resolution of the apparent incompatibility of the immunulogical changes with the generally favoured evolutionary perspective.

A theory which does not account for the reduced life expectancy would need to consider depressive illness to be an abnormal or dysfunctional extension of the adaptive emotional response. The social competition hypothesis ${ }^{4}$ proposed that depression signals submission, and acceptance of the resulting change in hierarchical ranking, to rivals in agonistic encounters, and that depression thereby facilitates survival. Another suggestion was that depression may originate from the failure to master an environmental threat, when it becomes adaptive to give up, withdraw, and get on with other activities, ${ }^{5}$ unless a dysfunctional prolonged deactivation or depression ensues.

In both these theories depression is a functional response which becomes abnormally severe and perhaps spontaneously occurring in major depressive illness. By contrast immunological resignation could involve a spectrum of response such that an individual without a significant predisposition would only develop physiological changes predisposing to death if circumstances were sufficiently severe, while others perhaps those with a genetic predisposition, adverse early experiences, and more recent significant life disruption would develop depression in less exacting circumstances. A major depressive illness would still be the spontaneous and inappropriate manifestation of these changes but depression itself would still be accompanied by adverse effects on health.

Support for the idea of a continuum - illhealth predisposition not only with the spontaneous occurrence of the severe, illness manifestation but also with the appropriate, adaptive response - comes from the observations that subordination in animals is associated with increased cortisol secretion ${ }^{6,7}$ and disruption of cortisol secretion is one of the earliest biochemical observations in severe depression. ${ }^{*}$ Cytokine changes in depression, especially in interleukin6 activity $^{9}$ and interleukin-Ib activity ${ }^{10}$ may be secondary to, or mediators of, the disruption of HPA activity. Maes et $\mathrm{al}^{11}$ consider that the low serum high density lipoprotein cholesterol (HDLC) seen in major depressive illness may be induced by the immune/inflammatory response in depression. Depression is known to be associated with an increased risk of myocardial infarction ${ }^{12}$ as well as reduced survival following myocardial infarction. ${ }^{13}$ Although it can be argued that both depression and ischaemic heart disease largely coincide because they both relate to inadequate 
intake of omega-3 polyunsaturated fatty acids ${ }^{14}$ this would not in itself make redundant an evolutionary hypothesis of depression as these fatty acids have been critically important in the development of the human brain. ${ }^{15}$

\section{References}

1. Abed RT. Suicide as altruism: a Darwinian perspective. Ir J Psych Med 1997 14(4): 144-6.

2. Dawkins R. The selfish gene. Oxford: Oxford University Press, 1976.

3. Corrigan FM. Depression: immunological resignation of the will to live? Medical Hypotheses 1998; 50: 9-18.

4. Price J, Sloman L, Gardner R, Gilbert P, Rohde P. The social competition hypothesis of depression. Br J Psychiatry 1994; 164: 309-15.

5. Clark LA, Watson D. Distinguishing functional from dysfunctional affective responses. In: The Nature of Emotion. Ekman P, Davidson RJ, eds. Oxford: Oxford University Press 1994: 131-146.

6. Jones IH, Stoddart DM, Mallick J. Towards a sociobiological model of depression: a marsupial model (Petaurus Breviceps). Br J Psychiatry 1995; 166 : 475-9.

7. Sapolsky RM. Adrenocortical function, social rank and personality among wild baboons. Biol Psychiatry 1990; 28: 862-87.

8. Sachar RJ, Hellman L, Roffwarg HP, Halpern FS, Fukushima DK, Gallagher TF. Disrupted 24 hour patterns of cortisol secretion in psychotic depression. TF. Disrupted 24 hour patterns of cortis

9. Maes M, Scharp S, Meltzer HY et al. Relationship between interleukin-6 activity, acute phase proteins and function of hypothalamic-pituitary-adrenal axis in severe depression. Psychiatry Res 1993; 49: 11-27.

10. Weizman R, Laor N, Podliszewski E, Notti I, Djaldetti M, Bessler M. Cytokine production in major depressed patients before and after clomipramine treatment. Biol Psychiatry 1994; 35: 42-7.

11. Maes M, Smith R, Christophe A et al. Lower serum high-density lipoprotein cholesterol (HDL-C) in major depression and in depressed men with serious suicidal attempts: relationship with immune-inflammatory markers. Acta Psychiatr Scand 1997; 95: 212-221.

12. Pratt LA, Ford DE, Crum RM, Armenian HK, Gallo JJ, Eaton WW. Depression, psychotropic medication and risk of myocardial infarction. Prospective data from the Baltimore ECA follow-up. Circulation 1996; 94 3123-9.

13. Frasure-Smith N, Lesperance F, Talajic M. Depression following myocardial infarction. Impact on six month survival. JAMA 1993 ; 270(15); 1819-25.

14. Hibbein JR, Salem N. Dietary polyunsaturated fatty acids in depression: when cholesterol does not satisfy. Am J Clin Nutr 1995; 62: 1-9.

15. Crawford MA. The role of dietary fats in biology: their place in the evolution of the human brain. Nutr Rev 1992; 50: 3-11.

Frank M Corrigan MB, ChB, MD, FRCPsych, Consultant Psychiatrist, Argyll and Bute NHS Trust, Argyll and Bute Hospital, Lochgilphead Argyll, PA3l 8LD, Scotland.

\section{Epilim ${ }^{\circledR}$ Oral Prescribing Information}

Presentation: Epilim 200 Enteric Coated and Epilim 500 Enteric Coated: Entericcoated tablets containing 200mg, and 500mg Sodium Valproate Ph.Eur. respectively. Epilim Crushable Tablets containing 100mg Sodium Valproate Ph.Eur. Epilim Syrup and Epilim Liquid (sugar-free) both containing 200mg Sodium Valproate Ph.Eur. per $5 \mathrm{ml}$. Epilim Chrono 200, Epilim Chrono 300, and Epilim Chrono 500: Controlledrelease tablets containing a mixture of Sodium Valproate Ph.Eur. and Valproic Acid Fr.P. equivalent to $200 \mathrm{mg}, 300 \mathrm{mg}$, and $500 \mathrm{mg}$ Sodium Valproate respectively. Indications: Oral formulations of Epilim are indicated for all types of epilepsy. Dosage and administration: Adults: the dose should be titrated at three day intervals until seizure control is achieved. Initially $600 \mathrm{mg}$ a day increasing in steps of $200 \mathrm{mg}$ to a maximum dose of $2500 \mathrm{mg}$ per day. Children over $20 \mathrm{~kg}$ : initially $400 \mathrm{mg}$ a day increasing in steps to a maximum dose of $35 \mathrm{mg} / \mathrm{kg} /$ day. Children under $20 \mathrm{~kg}$ : initially $20 \mathrm{mg} / \mathrm{kg} /$ day - the dose may be increased in severe cases provided that plasma levels are monitored; above $40 \mathrm{mg} / \mathrm{kg} /$ day chemistry and haematology should be monitored. Epilim Chrono may be given once or twice daily. All other formulations should be given twice daily. Combination therapy: Levels of Epilim and co-administered anticonvulsants may be affected and optimum dosage is determined by seizure control. Contra-indications, Warnings, etc.: Contra-indications: Active liver disease, family history of severe liver disease, hypersensitivity to valproate. Sideeffects: Impaired hepatic function, particularly in children, occasionally leading to hepatic failure - treatment should be withdrawn in patients who suddenly develop symptoms compatible with hepatic disease such as nausea, anorexia, jaundice or malaise. Hyperammonaemia with or without hepatic dysfunction. Blood dyscrasia impaired platelet function, thrombocytopenia, occasional leucopenia and red cell hypoplasia. Occasionally increased appetite, weight gain, transient hair loss, behavioural disturbances, alterations to the menstrual cycle and pancreatitis. Symptoms of intoxication include ataxia, tremor, and stupor. Drug interactions: Epilim has significant interactions with phenytoin, lamotrigine and other anticonvulsants. Epilim may potentiate the effects of neuroleptics, MAOIs and other antidepressants, anticoagulants and salicylates. Cimetidine may inhibit the metabolism of Epilim. Epilim has no effect on the efficacy of oral contraceptives. Pregnancy: An increased incidence of congenital abnormalities has been demonstrated in offspring born to mothers with epilepsy both untreated and treated, including those treated with sodium valproate. Neural tube defects have been reported in about $1 \%$ of offspring of women who have received valproate during the first trimester of pregnancy. Pregnancies should be screened for neural tube defects by estimation of alpha-fetoprotein and ultrasound. Folate supplementation has been shown to reduce the incidence of neural tube defects in the offspring of high-risk women in general. Legal category: POM. Further information: Epilim is hygroscopic - tablets should not be removed from their foil until they are used. Epilim Chrono is recommended in cases where plasma valproate levels are being measured on account of its pharmacokinetics. The effective therapeutic range for valproate is $40-100 \mathrm{mg} / \mathrm{l}$ (278-694 micromol/1). Product Authorisation Numbers: Epilim 200 Enteric Coated 77/113/1, Epilim 500 Enteric Coated 77/113/2, Epilim 100mg Crushable Tablets 77/113/5, Epilim Syrup 77/113/4, Epilim Liquid 77/113/6, Epilim Chrono 200 77/113/9, Epilim Chrono $30077 / 113 / 8$, Epilim Chrono 500 77/113/10. Address: Sanofi Winthrop Ireland Ltd., United Drug House, Belgard Rd, Tallaght, Dublin 24

Telephone: (01) 4598877 . Fax: (01) 4621855

Epilim, Epilim Chrono and the Chrono device are registered trade marks.

Date of preparation: 29 August 1996

References: 1. Chadwick D., J. Neurol. Neurosurg.

Psychiatry 1994; 57: 264-277.

2. Gillham R.A., Epilepsy Res., 1990; 7: 219-225. 